\title{
COMPOSIÇÃO ISOTÓPICA DE CARBONO E OXIGÊNIO DOS VEIOS DE MAGNESITA MICROCRISTALINA DO MORRO DO NÍQUEL
}

\author{
T.I.R.Almeida ${ }^{1}$ \\ M.L.M.Carvalho e Silva ${ }^{2}$
}

O maciço ultrabásico serpentinizado do Morro do Níquel, com depósitos lateríticos de Ni, ocorre encaixado em rochas do Complexo Campos Gerais. Está localizado na porção SW do Estado de Minas Gerais, no município de Pratápolis. O perfil típico da jazida mostra, do topo para a base, uma delgada camada de cobertura lateritica, um espêsso nível de silcrete e, eventualmente, bolsões de material ferruginoso antes do nivel saprolitico da base do perfil (OLIVEIRA, 1990 - Tese de Livre Docência, Instituto de Geociêncais, USP), que constitui o minério silicatado e onde ocorrem, localizadamente, os veios de magnesita ora estudados. Estes veios constituem-se de material pulverulento, branco leitoso, encaixados em porções silicificadas do saprólito. Análises por difração de raio $\mathrm{X}$ mostraram serem constituídos essencialmente por magnesita, com impurezas de mineral do tipo do talco. Ao microscópio ótico esses veios revelam magnesita microcristalina, sem identificação de outros minerais, por vezes em contato direto com veios de quartzo mas sem interdigitação. Presença de carbonatos, na base dos perfis de alteração de depósitos brasileiros de níquel laterítico, são descritos por diversos autores, embora não tenham sido privilegiados em estudos genéticos. COLIN et al. (1990; Economic Geology, 85:1010-1023) entretanto, observam que, em Niquelândia, veios de magnesita encontram-se presentes apenas nas porções de piroxenitos fortemente serpentinizados. $\mathrm{Na}$ literatura brasileira não se encontram trabalhos isotópicos sobre veios de magnesita deste tipo, relativamente bem estudados por pesquisadores europeus.

Após exames petrográficos e de raio $X$, duas amostras foram moídas a 150\#m,

\footnotetext{
${ }_{1}^{1}$ Departamento de Geologia Econômica e Geofísica Aplicada, Instituto de Geociências, USP.

2Pós-graduação, Departamento de Geologia Geral, Instituto de Geociências, USP.
} 
duplicadas e encaminhadas ao CENA-USP para análise da composição isotópica de $\mathrm{C}$ e O. Utilizou-se para a abertura das amostras o procedimento descrito por PERRY \& TAN (1972; Geol.Soc.Am.Bull., 83:647-664), com ataque por $\mathrm{H}_{3} \mathrm{PO}_{4}$ a $100 \%$, a $50^{\circ} \mathrm{C}$ por 72 horas. $\mathrm{O} \mathrm{CO}_{2}$ extraído foi analisado por espectrômetro de massa contra padrão PDB com os resultados de $\delta^{18} 0$ sofrendo as correções devidas ao fracionamento cinético nas condições analfticas utilizadas.

Os resultados finais foram os seguintes pares, respectivamente $\delta^{18} \mathrm{O}_{\mathrm{vsmow}} \mathrm{e}$ $\delta^{13} C_{\text {PDB }}$ em \%: $+26,58 \pm 0,01$ e $-11,35 \pm 0,01$ e $+26,42 \pm 0,01$ e $-15,50 \pm 0,01$. Estes resultados, comparados com os da revisão de KRALIK et al. (1989; Monograph Series on Mineral Deposits, 28:197-223), mostram-se típicos de magnesitas de origem supérgena. Segundo aquele trabalho a composição de magnesitas microcristalinas em rochas ultramáficas apresenta uma tendência de comportamento muito definida, com $\delta^{18} O_{\text {vsmow }}$ entre +22 e $+29 \%$ e $\delta^{13} C_{P D B}$ entre -4 e $-20 \%$ 。 (com nftida concentração entre -9 e $-12 \%$ ). Os $\delta 180$ encontrados indicam a formação da magnesita em baixas temperaturas, ao longo de fraturas, pela circulação de águas subsuperficiais. Já o $\delta^{13} \mathrm{C}$ indica condições de saturação de $\mathrm{CO}_{3}{ }^{2-}$ e regimes de $\mathrm{PCO}_{2}$ e pH especfficos, descartando-se a possibilidade de participação de fluidos de origem magmática, que enriqueceriam os carbonatos em ${ }^{13} \mathrm{C}$. Em carbonatos superficiais haveria a tendência de maior equilíbrio com o $\mathrm{CO}_{2}$ atmosférico, com $\delta^{13} \mathrm{C}$ da ordem de $-7 \%$. Estes valores indicam, portanto, uma origem da magnesita a partir de águas meteóricas e em condições sub-superficiais. 